\title{
UNA ESPECIE NUEVA DE TILLANDSIA (Bromeliaceae) de Guerrero, México
}

\author{
María Flores-Cruz ${ }^{1,2,3}$ y María Valentina Diego-Escobar ${ }^{1}$ \\ 'Programa de Botánica, Instituto de Recursos Naturales, Colegio de Postgraduados, \\ 56230 Montecillo, Estado de México, México \\ ${ }^{2}$ Departamento de Biología, División de Ciencias Biológicas y de la Salud, \\ Universidad Autónoma Metropolitana-Iztapalapa, Apartado Postal 55-535, 09340 México, D.F., México \\ ${ }^{3}$ Autor para la correspondencia. Correo-e: mafc@xanum.uam.mx
}

\begin{abstract}
Resumen: Se describe e ilustra a Tillandsia fascifolia, una nueva especie del estado de Guerrero, México. El nuevo taxón es similar morfológicamente a especies como T. bartramii, T. chaetophylla, T. eistetteri, T. festucoides, T. juncea, T. ortgiesiana, T. pentasticha y $T$. setacea. Sin embargo, caracteres tales como el color naranja de las brácteas florales, los sépalos verdes hacia la base y naranja hacia el ápice y los pétalos blancos hacia la base y verde claro hacia el ápice la distinguen del resto. Crece como epífita sobre encinos en bosques mesófilos de montaña y en bosques de pino-encino.
\end{abstract}

Palabras clave: bosque mesófilo de montaña, bosque de pino-encino, epífita, Tillandsia fascifolia.

Abstract: Tillandsia fascifolia is described and illustrated from plants collected in the state of Guerrero, Mexico. The new taxon is similar to species such as T. bartramii, T. chaetophylla, T. eistetteri, T. festucoides, T. juncea, T. ortgiesiana, T. pentasticha and T. setacea. However, characters such as an orange color of floral bracts, green sepals at base and orange at apex and white petals at base and pale green at apex. It grows as an epiphyte over oak trees in cloud forests and pine-oak forests.

Keywords: epiphyte, cloud forest, montane forest, pine-oak forest, Tillandsia fascifolia.

$\mathbf{E}^{1}$ género Tillandsia se caracteriza por poseer hojas enteras, lores bisexuales con los sépalos connatos, rara vez libres, los pétalos libres sin apéndices, los estambres exsertos o insertos, el ovario súpero, el fruto una cápsula septicida y las semillas con comas basales. Comprende alrededor de 540 especies (Luther, 2000; Espejo-Serna et al., 2004) y en México se reconocen alrededor de 170 , de las cuales más de la mitad son endémicas del país (García-Franco, 1987; Flores-Cruz, 1998; Espejo y López-Ferrari, 1998; Sandoval-Bucio et al., 2004; Diego-Escobar, 2005). El género es americano, al igual que toda la familia, excepto una especie, Pitcairnia feliciana, que se encuentra en el oeste de África (Smith y Downs, 1977). La mayor diversidad se localiza en los trópicos y subtrópicos, con algunos taxones que se extienden a zonas cálido-templadas. Existe un claro centro de diversidad del género en el centro y sur de México (Utley, 1994).

Durante la revisión de especímenes de los herbarios CHAPA, CODAGEM, ENCB, FCME y MEXU, y la recolección de material botánico para la preparación del fascículo sobre Bromeliaceae de la Flora de Guerrero, se encontró una especie del género Tillandsia que debido a sus características se propone como nueva.

Tillandsia fascifolia M. Flores-Cruz et V. Diego-Escobar sp. nov. Figuras 1 y 2 .

Folia fasciculata rosulis infundibuliformibus, ferrugineolepidota appressa; inflorescentia bipinnata, subdigitata; bracteae aurantiacae, imbricatae, lepidotae; flores sessiles; sepala postica carinata, connata in dimidio inferiore; petala erecta, albida base, pallide viridia apice; stamina exserta inaequalia.

TIPO: México, Guerrero. Municipio Malinaltepec, km 45 de la carretera Tlapa-Malinaltepec, $17^{\circ} 17.6^{\prime} \mathrm{N}, 98^{\circ} 38.19^{\prime}$ O, alt. 2,200 m, bosque de Quercus, 17 abril 2004, V. DiegoEscobar, M. Flores-Cruz, F. Riveros y J. Lara-Sánchez 93 (Holotipo: CHAPA; Isotipos: MEXU, ENCB, MO). 
María Flores-Cruz y María Valentina Diego-Escobar

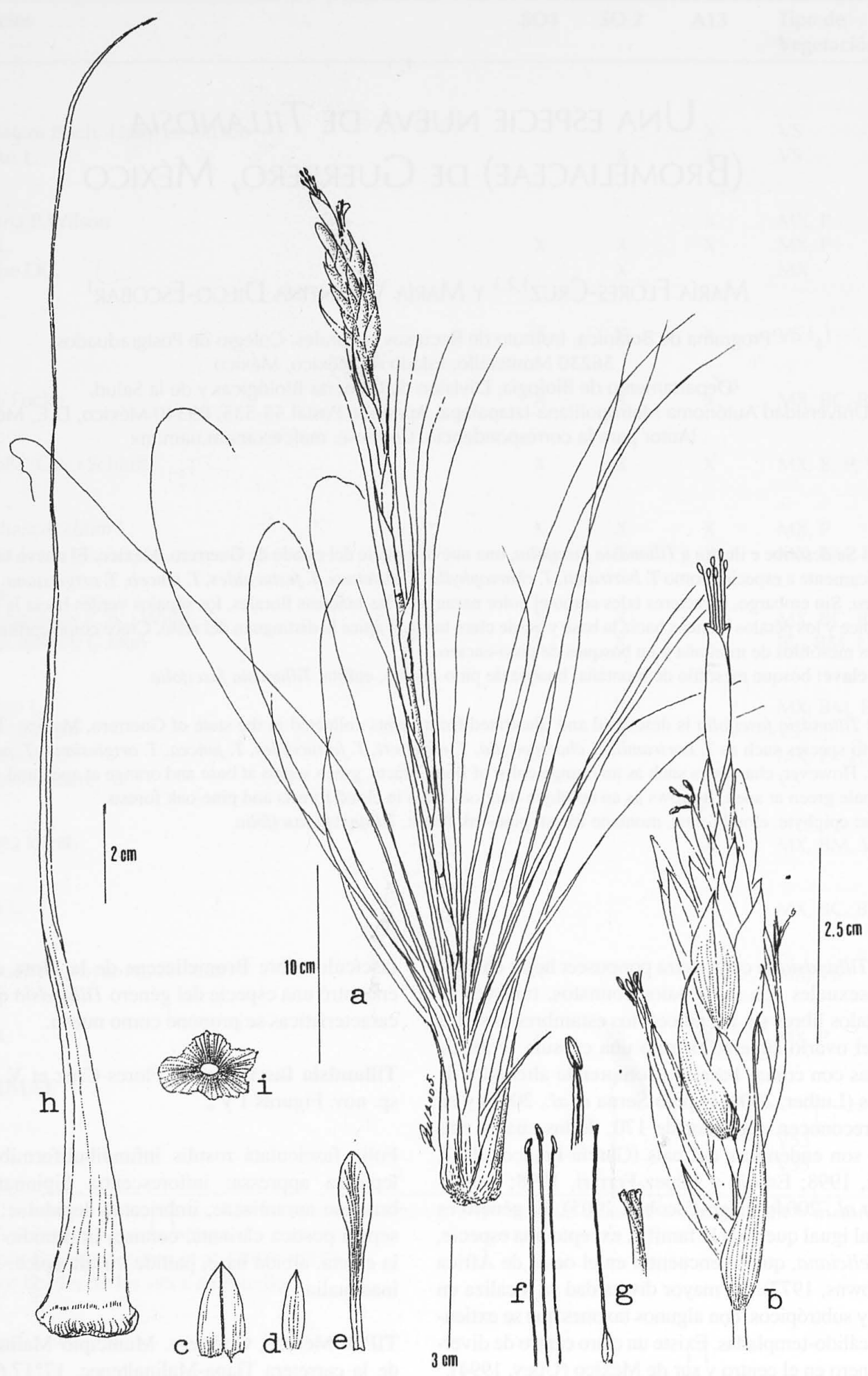

Figura 1. Tillandsia fascifolia. a. Vista general de la planta. b. Inflorescencia y brácteas de las ramas. c. Bráctea floral carinada d. Sépalo carinado e. Pétalo espatulado f. Estambres de longitud diferente y anteras sub-basifijas. g. Pistilo y estigma espiral-conduplicado. h. Vista de la hoja completa. i. Tricoma de la hoja. 


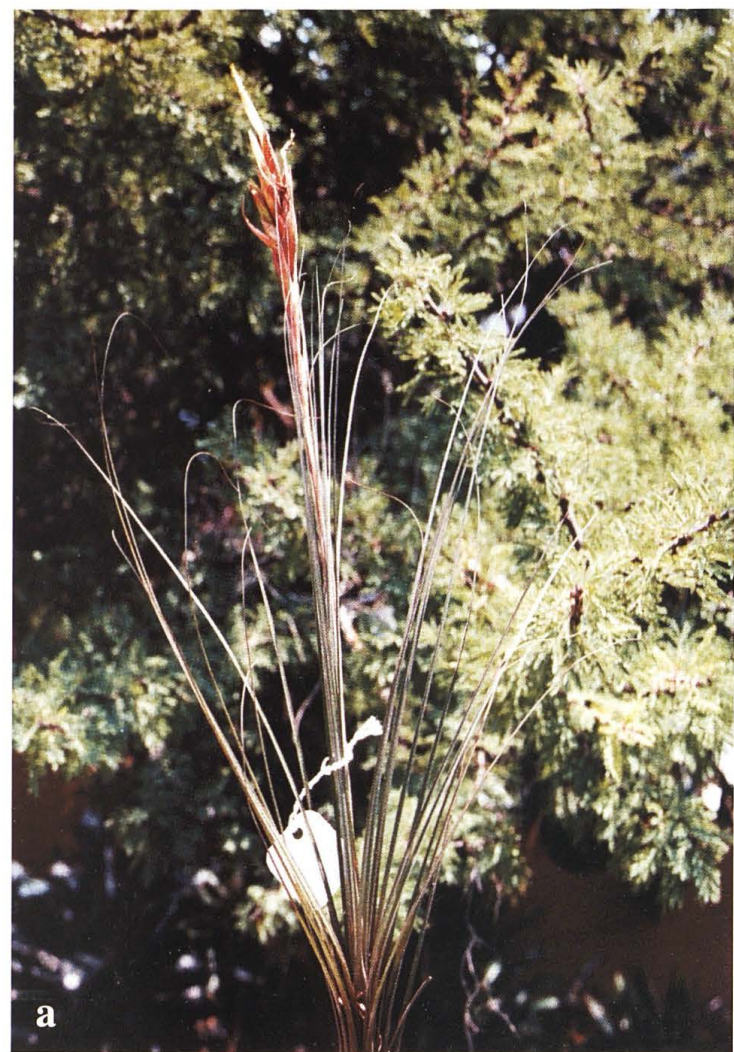

Hierbas epífitas de 41 a $60 \mathrm{~cm}$ incluyendo la inflorescencia, agrupadas, acaules, sin estolones. Hojas subcoriáceas, suaves, fasciculadas en una roseta infundibuliforme, de 30.5 a $55.5 \mathrm{~cm}$ de largo, marcadamente nervadas cuando secas y finamente nervadas en fresco, más largas o más cortas que la inflorescencia; vainas triangulares, de 2 a $3.5 \mathrm{~cm}$ de largo, de 1 a $1.4 \mathrm{~cm}$ de ancho, parduscas, densamente ferrugíneolepidoto-adpresas, subamplexicaules, con el margen membranáceo; láminas cinéreo-verdosas, ascendentes, lineares, acanaladas, de 28 a $52 \mathrm{~cm}$ de largo, de 5 a $9 \mathrm{~mm}$ de ancho, lepidoto-adpresas, el margen fuertemente involuto. Escapo delgado, más corto que las hojas, de 29 a $48.5 \mathrm{~cm}$ de largo, recto, glabro; brácteas del escapo adpresas, imbricadas, amplexicaules, las inferiores foliáceas, las superiores anaranjadas, con la lámina más corta, subcoriáceas. Inflorescencias creciendo en distintas direcciones, bipinnadas, erectas, subdigitadas, de 6.2 a $9.2 \mathrm{~cm}$ de largo, de 1.8 a $4 \mathrm{~cm}$ de ancho, de 4 a 8 ramas; raquis recto, de 2 a $7 \mathrm{~cm}$ de 1 largo; brácteas de las ramas color naranja, con una lámina corta, subcoriáceas, lepidoto-adpresas, ascendentes; vainas de 2.2 a $3.5 \mathrm{~cm}$ de largo, más cortas que las ramas axilares; ramas subcilíndricas, elípticas, con 2 a 5(9) flores, de 3.5 a $5.7 \mathrm{~cm}$ de largo, de 1 a $2 \mathrm{~cm}$ de ancho, adpresas, con 2 a 3 brácteas

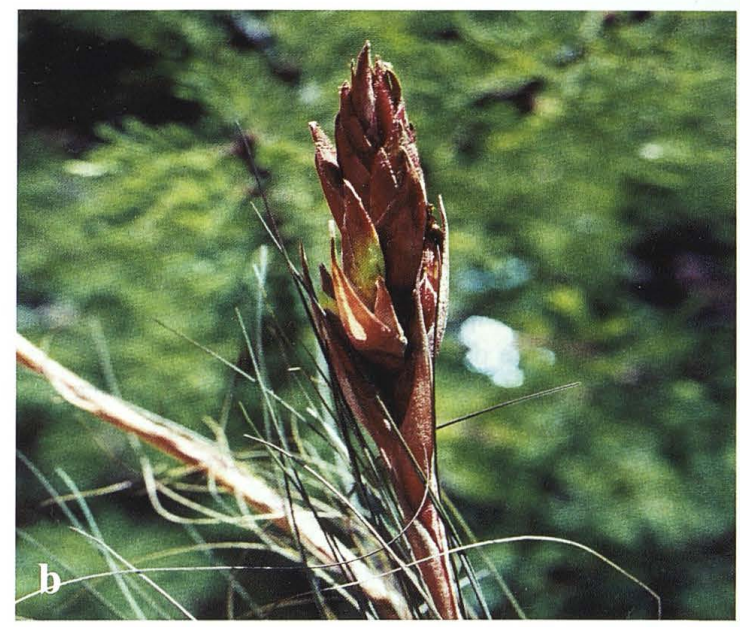

Figura 2. Tillandsia fascifolia. a. Hojas fasciculadas de la roseta. b. Brácteas florales color naranja y flores color verde claro.

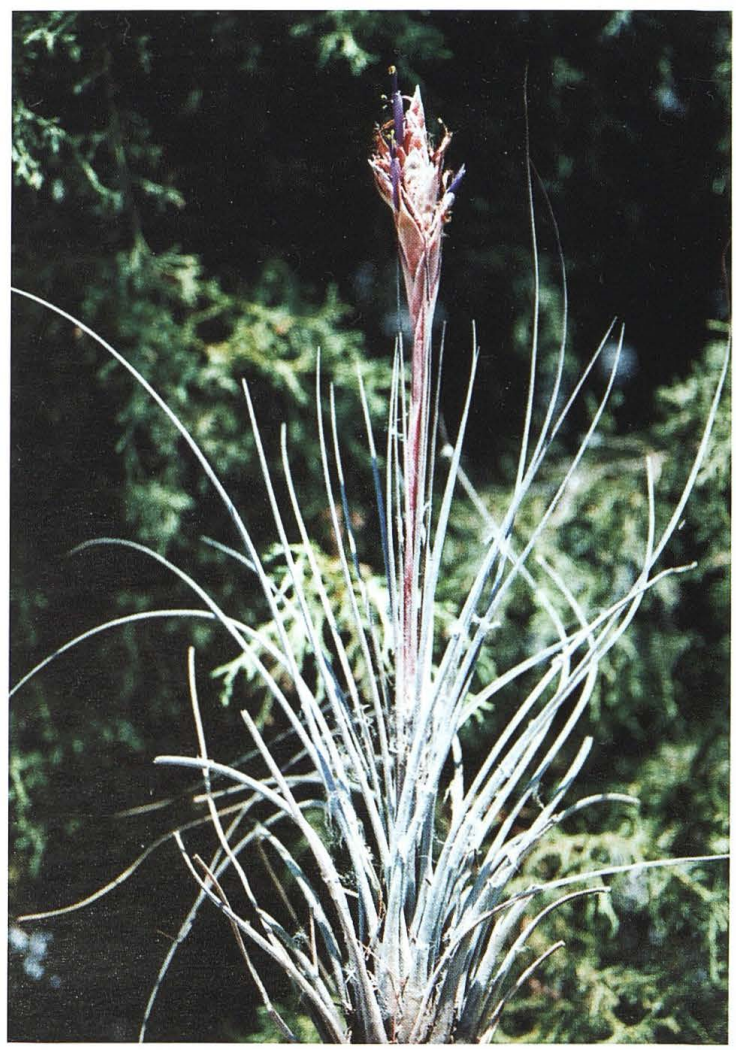

Figura 3. Tillandsia juncea. Brácteas florales de color púrpura y pétalos morados. 
basales estériles, subsésiles, con un estípite de 2 a $6 \mathrm{~mm}$ de largo; brácteas florales color naranja, iguales o escasamente más largas que los sépalos, ovadas, marcadamente nervadas, adpresas, carinadas, de 2 a $2.5 \mathrm{~cm}$ de largo, de 0.8 a $1.3 \mathrm{~cm}$ de ancho, imbricadas, subcoriáceas, esparcidamente lepidotas en el margen. Flores sésiles, ascendentes; sépalos verdes hacia la base y naranja hacia el ápice, los dos posteriores carinados y connatos hacia la base, el interior ecarinado y libre, elípticos, simétricos, de 1.7 a $2.5 \mathrm{~cm}$ de largo, de 5 a $6 \mathrm{~mm}$ de ancho, marcadamente nervados, esparcidamente lepidotos en el ápice; pétalos blancos hacia la base, verde claro hacia el ápice, espatulados, ápice obtuso y revoluto, de 4.6 a $5.1 \mathrm{~cm}$ de largo, de 5 a $6 \mathrm{~mm}$ de ancho; estambres exsertos, de longitud diferente; filamentos de 4.4 a $6.3 \mathrm{~cm}$ de largo, blancos hacia la base, verde claro hacia el ápice; anteras elípticas, sub-basifijas, de 2 a $3 \mathrm{~mm}$ de largo, polen y conectivo de las anteras amarillos; pistilo de 5.6 a $6.2 \mathrm{~cm}$ de largo, ovario verde, de 6 a $7 \mathrm{~mm}$ de largo, estilo blanco hacia la base, verde claro hacia el ápice, estigma verde, espiral conduplicado. Frutos y semillas desconocidos.

Distribución y ecología. Esta especie se conoce únicamente del este del estado de Guerrero, en una zona cercana al estado de Oaxaca. A la fecha sólo se ha observado de la localidad tipo y de las dos colectas referidas. Es una hierba que crece como epífita sobre árboles de Quercus, y que habita en lugares húmedos de bosques de Pinus-Quercus y bosque mesófilo de montaña, entre 2,200 y 2,440 m s.n.m. Florece de enero a abril. No se han observado aún plantas con fruto.

El epíteto específico se relaciona con la disposición fasciculada de las hojas, característica distintiva del Grupo I, Subgrupo IV propuesto por Gardner $(1982,1986)$ en su revisión taxonómica de Tillandsia.

Ejemplares adicionales examinados: México, Guerrero, Municipio Malinaltepec, $5.5 \mathrm{~km}$ al NNO de Iliatenco, alt. 2,400 m, bosque de Pinus-Quercus, 23 marzo 1982, M.P. Ochoa s. n. (FCME); Tres Marías, 177'25' N, 98 41'30.9' O, alt. 2,440 m, bosque mesófilo de montaña, 29 enero 2006, $\mathbf{R}$. Bustamante, L. Lozada et al. 57 (FCME).

De acuerdo con la clasificación preliminar de Gardner (1986), Tillandsia fascifolia se ubica en el Grupo I, Subgrupo IV, que incluye a $T$. bartramii Elliott, $T$. chaetophylla Mez, $T$. festucoides Brongn. ex Mez, T. juncea (Ruiz et Pav.) Poir., $T$. ortgiesiana E. Morren y T. setacea $\mathrm{Sw}$. Dos especies más se incluyen en este grupo, $T$. pentasticha Rauh et Wülfinghoff, publicada en 1988, y T. eistetteri Ehlers, publicada en 1991 (cuadro 1). En conjunto, el grupo se caracteriza por su hábito epífito o saxícola, de moderado a fuertemente xeromorfo; se distribuye desde el nivel del mar hasta 2,500 $\mathrm{m}$ de altitud. Son plantas acaules, rara vez estoloníferas, con las hojas fasciculadas en una roseta infundibuliforme, con las vainas reducidas y triangulares, y las láminas de las hojas lineares. La inflorescencia es bipinnada, rara vez unipinnada, con un escapo evidente; las ramas son erectas o extendidas a un ángulo de 45 grados. Las flores tienen una posición horizontal o ascendente. Los pétalos son espatulados, con lóbulos cerrados y un ápice revoluto; los estambres son exsertos, los filamentos son concoloros con la corola, las anteras son sub-basifijas (Gardner, 1982, 1986) y el estigma es del tipo espiral-conduplicado (tipo II sensu Brown y Gilmartin, 1984, 1989). Las flores de las especies del Subgrupo IV tienen características ornitófilas, con flores que sobresalen del follaje, generalmente inodoras, con corolas tubulares con abundante néctar, y estambres y pistilos exsertos (Faegri y van der Pijl, 1979; Eguiarte, 1983).

Los miembros del subgrupo se asocian principalmente por el tipo de roseta (cuadro 1); las hojas presentan vainas cortamente triangulares y láminas lineares; la mayoría tiene inflorescencias terminales y bipinnadas, con un escapo alargado. No obstante, Tillandsia fascifolia se distingue de las otras especies del subgrupo por el color naranja de las brácteas florales, los sépalos verdes hacia la base y naranja hacia el ápice y los pétalos blancos hacia la base y verde claro hacia el ápice, en tanto que en las otras especies, las brácteas florales son verdes, rosadas, rojas, rojo carmín y púrpura; los sépalos son claramente verdosos hacia la base, rosados hasta rojo carmín hacia el ápice; los pétalos son de color morado, lila y rojo, y en algunos casos se presentan blancos hacia la base (cuadro 1).

Las especies del Subgrupo IV, como se describió anteriormente, poseen varias características florales distintivas; sin embargo, Tillandsia fascifolia parece estar más relacionada con $T$. juncea por la forma fusiforme de la inflorescencia. La primera se distingue de la segunda por carecer de estolones, el color blanco hacia la base y verde claro hacia el ápice de los pétalos, el tamaño de éstos, de 4.6 a $5.1 \mathrm{~cm}$ de largo, el estigma concoloro con la corola y el color amarillo del conectivo de las anteras. En la segunda, las plantas son estoloníferas, los pétalos son blancos hacia la base y púrpura hacia el ápice, de 2.5 a $3.5 \mathrm{~cm}$ de largo, el color del estigma y la corola son diferentes y el conectivo de las anteras es de color negro (cuadro 1; figuras 2 y 3). Tillandsia fascifolia está restringida al estado de Guerrero, en tanto que Tillandsia juncea tiene una distribución amplia, desde México hasta Sudamérica (cuadro 1).

\section{Agradecimientos}

Las autoras desean expresar su agradecimiento por la cuidadosa revisión del manuscrito y por las acertadas sugerencias de Nelly Diego, S.D. Koch y Abisaí García Mendoza. Asimismo, se agradece a W. Till el envío de algunas descripciones originales y fototipos. A Heike Vibrans, porque amablemente tradujo algunas descripciones originales del alemán al español. A Ramiro Cruz por la elaboración de la 
Nueva especie de TillandSIA De GuerRero

Cuadro 1. Comparación morfológica de Tillandsia fascifolia con especies relacionadas.

\begin{tabular}{|c|c|c|c|c|c|c|c|c|c|}
\hline & T. fascifolia & T. bartramii & T. chaetophylla & T. eistetteri & T. festucoides & T. juncea & T. ortgiesiana & T. pentasticha & T. setacea \\
\hline Estolones & ausentes & ausentes & presentes & ausentes & ausentes & presentes & presentes & presentes & ausentes \\
\hline $\begin{array}{l}\text { Láminas } \\
\text { foliares } \\
\text { lineares }\end{array}$ & $\begin{array}{l}28 \text { a } 52 \times 0.5 \\
\text { a } 0.9 \mathrm{~cm}\end{array}$ & $\begin{array}{l}15.5 \mathrm{a} \\
40 \times(0.2) \\
0.3 \mathrm{a} 0.7 \mathrm{~cm}\end{array}$ & $\begin{array}{l}23 \text { a } 30 \times 0.2 \\
\mathrm{~cm}\end{array}$ & $\begin{array}{l}7 \text { a } 10 \times 0.5 \\
\mathrm{~cm}\end{array}$ & $\begin{array}{l}20 \text { a } 38 \times 0.1 \\
\text { a } 0.4 \mathrm{~cm}\end{array}$ & $\begin{array}{l}18 \text { a } 55 \times 0.5 \\
\text { a } 1.2 \mathrm{~cm}\end{array}$ & $\begin{array}{l}23 \text { a } 30.8 \times 0.8 \\
\text { a } 1.0 \mathrm{~cm}\end{array}$ & $\begin{array}{l}17.1 \text { a } 50.1 x \\
0.5 \text { a } 1.0 \mathrm{~cm}\end{array}$ & $\begin{array}{l}19 \text { a } 40 \times 0.2 \\
\text { a } 0.4 \mathrm{~cm}\end{array}$ \\
\hline Escapo & $\begin{array}{l}\text { más corto que } \\
\text { las hojas, } 29 \text { a } \\
48.5 \mathrm{~cm} \text { de } \\
\text { largo }\end{array}$ & $\begin{array}{l}\text { más corto que } \\
\text { las hojas, } 10 \text { a } \\
27.5 \mathrm{~cm} \text { de } \\
\text { largo }\end{array}$ & $\begin{array}{l}\text { más corto o más } \\
\text { largo que las } \\
\text { hojas, } 12 \text { a } 27.5 \\
\text { cm de largo }\end{array}$ & $\begin{array}{l}\text { igual o escasa- } \\
\text { mente más } \\
\text { largo que las } \\
\text { hojas, } 10 \text { a } 15 \\
\text { cm de largo }\end{array}$ & $\begin{array}{l}\text { más corto que } \\
\text { las hojas, } 22 \text { a } \\
30 \mathrm{~cm} \text { de largo }\end{array}$ & $\begin{array}{l}\text { más corto o } \\
\text { más largo que } \\
\text { las hojas, } 13.8 \\
\text { a } 41 \mathrm{~cm} \text { de } \\
\text { largo }\end{array}$ & $\begin{array}{l}\text { más largo que } \\
\text { las hojas, } 37.5 \\
\text { cm de largo }\end{array}$ & $\begin{array}{l}\text { igual, más corto } \\
\text { o mas largo que } \\
\text { las hojas, } 24.5 \\
\text { a } 48.1 \mathrm{~cm} \text { de } \\
\text { largo }\end{array}$ & $\begin{array}{l}\text { igual o más } \\
\text { corto que las } \\
\text { hojas, } 12.9 \text { a } \\
27 \mathrm{~cm} \text { de } \\
\text { largo }\end{array}$ \\
\hline Inflorescencia & $\begin{array}{l}\text { bipinnada } \\
\text { de } 4 \text { a } 8 \text { ramas } \\
\text { subcilíndricas, } \\
\text { con } 2 \text { a } 5 \text { (9) } \\
\text { flores, elípticas, } \\
\text { ramas de } 3.5 \text { a } \\
5.7 \text { cm de largo }\end{array}$ & $\begin{array}{l}\text { bipinnada } \\
\text { de } 2 \text { a } 4 \text { ramas } \\
\text { complanadas, } \\
\text { con } 3 \text { a } 6 \text { flores, } \\
\text { lanceoladas, } \\
\text { ramas de } 3.3 \text { a } \\
9 \text { cm de largo }\end{array}$ & $\begin{array}{l}\text { unipinnada } \\
1 \text { rama } \\
\text { complanadas, } \\
\text { con } 2 \text { a } 10 \\
\text { flores, elípticas, } \\
\text { ramas de } 4 \text { a } 8 \\
\text { cm de largo }\end{array}$ & $\begin{array}{l}\text { bipinnada } \\
\text { de } 2 \text { a } 5 \text { ramas } \\
\text { subcilíndricas } \\
\text { con } 1 \text { a } 3 \text { flores } \\
\text { angostamente } \\
\text { elípticas, } \\
\text { ramas de } 1.5 \text { a } \\
3.5 \mathrm{~cm} \text { de largc }\end{array}$ & $\begin{array}{l}\text { bipinnada } \\
\text { de } 4 \text { a } 5 \text { ramas } \\
\text { complanadas, } \\
\text { con } 2 \text { a } 5 \text { flores, } \\
\text { lineares, ramas } \\
\text { de } 3 \text { a } 9 \mathrm{~cm} \\
\text { de largo }\end{array}$ & $\begin{array}{l}\text { bipinnada de } \\
3 \text { a } 12 \text { ramas } \\
\text { subcilíndricas, } \\
\text { con } 2 \text { a } 4, \\
\text { flores } \\
\text { lanceoladas, } \\
\text { ramas de } 2 \text { a }\end{array}$ & $\begin{array}{l}\text { bipinnada, } \\
\text { de } 2 \text { a } 8 \text { ramas } \\
\text { complanadas, } \\
\text { con } 8 \text { flores, } \\
\text { angostamente } \\
\text { elípticas, } \\
\text { ramas de } 5 \mathrm{~cm} \\
\text { de largo }\end{array}$ & $\begin{array}{l}\text { bipinnada, rara } \\
\text { vez unipinnada } \\
\text { con } 2 \text { a } 3 \text { ramas } \\
\text { complanadas, } \\
\text { con (3) } 4 \text { a } 7 \text { flo- } \\
\text { res, angostamen- } \\
\text { te lanceoladas, } \\
\text { ramas de } 4.8 \text { a } \\
\text { de largo }\end{array}$ & $\begin{array}{l}\text { bipinnada } \\
\text { de } 1 \text { a } 3 \text { ramas } \\
\text { subcilíndricas, } \\
\text { con } 3 \text { a } 4 \text { flores, } \\
\text { elípticas, ramas } \\
\text { de } 3.5 \text { a } 4 \mathrm{~cm} \\
\text { de largo }\end{array}$ \\
\hline $\begin{array}{l}\text { Brácteas } \\
\text { florales }\end{array}$ & $\begin{array}{l}\text { anaranjadas, } \\
\text { ovadas, } \\
2 \text { a } 2.5 \mathrm{~cm} \text { de } \\
\text { largo }\end{array}$ & $\begin{array}{l}\text { verdes hacia } \\
\text { la base, rosadas } \\
\text { hacia el ápice, } \\
\text { ovadas, } \\
1.6 \mathrm{~cm} \text { de largo }\end{array}$ & \begin{tabular}{|l|} 
rosado pálido \\
o rosado intenso \\
o rojas, lanceo- \\
ladas, 2.4 a 4.2 \\
cm de largo
\end{tabular} & $\begin{array}{l}\text { rojas o verdes, } \\
\text { ovadas, } \\
1.4 \text { a } 2 \mathrm{~cm} \text { de } \\
\text { largo }\end{array}$ & $\begin{array}{l}\text { rojas, } \\
\text { lanceolado- } \\
\text { ovadas, } \\
1.7 \text { a } 2.2 \mathrm{~cm} \\
\text { de largo }\end{array}$ & \begin{tabular}{|} 
verdes hacia la \\
base, púrpura \\
hacia el ápice, \\
ovadas, $1.8 \mathrm{a}$ \\
$2 \mathrm{~cm}$ de largo
\end{tabular} & $\begin{array}{l}\text { ovadas, } \\
2 \text { a } 2.5 \mathrm{~cm} \\
\text { de largo }\end{array}$ & $\begin{array}{l}\text { rojo carmín, } \\
\text { triangulares, } \\
2 \text { a } 3 \mathrm{~cm} \text { de } \\
\text { largo }\end{array}$ & $\begin{array}{l}\text { verdes, ovadas, } \\
1.4 \text { a } 1.8 \mathrm{~cm} \\
\text { de largo }\end{array}$ \\
\hline Sépalos & \begin{tabular}{|l|} 
verdes, \\
connatos los \\
posteriores \\
hacia la base, \\
elípticos, \\
1.7 a $2.5 \mathrm{~cm}$ \\
de largo, \\
marcadamente \\
nervados
\end{tabular} & $\begin{array}{l}\text { verdes, } \\
\text { connatos los } \\
\text { posteriores } \\
\text { hacia la base, } \\
\text { elípticos } \\
1.3 \text { a } 1.5 \mathrm{~cm} \\
\text { de largo, } \\
\text { lisos o } \\
\text { débilmente } \\
\text { nervados }\end{array}$ & \begin{tabular}{|l|} 
verdes hacia la \\
base, rosados \\
hacia el ápice, \\
connatos los pos- \\
teriores hacia la \\
base, lanceola- \\
dos, 2.9 a 3.2 \\
cm de largo, \\
marcadamente \\
nervados
\end{tabular} & $\begin{array}{l}\text { verdes, } 3 \\
\text { libres, } \\
\text { lanceolados, } \\
1.5 \mathrm{~cm} \text { de } \\
\text { largo }\end{array}$ & \begin{tabular}{|l|} 
connatos los \\
posteriores \\
hacia la base, \\
lanceolados, \\
$1.7 \mathrm{~cm}$ \\
de largo, \\
marcadamente \\
nervados
\end{tabular} & $\begin{array}{l}\text { verdes, } \\
\text { connatos los } \\
\text { posteriores } \\
\text { hacia la base, } \\
\text { elípticos, } \\
1.5 \text { a } 2 \text { cm de } \\
\text { largo, incons- } \\
\text { picuamente } \\
\text { nervados }\end{array}$ & $\begin{array}{l}\text { verdes, } \\
\text { connatos los } \\
\text { posteriores } \\
\text { hacia la base, } \\
\text { lanceolados, } \\
2.1 \mathrm{~cm} \text { de } \\
\text { largo, } \\
\text { marcadamente } \\
\text { nervados }\end{array}$ & $\begin{array}{l}\text { rojo carmín, } \\
\text { connatos los } \\
\text { posteriores } \\
\text { hacia la base, } \\
\text { lanceolados, } \\
2 \text { a } 2.5 \text { de } \\
\text { largo, } \\
\text { marcadamente } \\
\text { nervados }\end{array}$ & $\begin{array}{l}\text { verdes, } \\
\text { connatos los } \\
\text { posteriores } \\
\text { hacia la base, } \\
\text { elíptico- } \\
\text { oblongos, } \\
0.7 \text { a } 1.2 \mathrm{~cm} \\
\text { de largo, } \\
\text { marcadamente } \\
\text { nervados }\end{array}$ \\
\hline Pétalos & $\begin{array}{l}\text { blancos hacia } \\
\text { la base, verde } \\
\text { claro hacia el } \\
\text { ápice, } 4.6 \text { a } 5.1 \\
\text { cm de largo }\end{array}$ & $\begin{array}{l}\text { morados, } \\
3 \text { a } 4.5 \mathrm{~cm} \text { de } \\
\text { largo }\end{array}$ & $\begin{array}{l}\text { blancos hacia } \\
\text { la base, lilas o } \\
\text { morados hacia } \\
\text { el ápice, } 4.8 \text { a } 7 \\
\text { cm de largo }\end{array}$ & $\begin{array}{l}\text { blancos hacia } \\
\text { la base, rojos } \\
\text { hacia el ápice, } \\
3 \text { a } 3.5 \mathrm{~cm} \\
\text { de largo }\end{array}$ & $\begin{array}{l}\text { morados, } \\
2.5 \text { a } 3 \mathrm{~cm} \\
\text { de largo }\end{array}$ & $\begin{array}{l}\text { blancos hacia } \\
\text { la base, mora- } \\
\text { dos hacia el } \\
\text { ápice, } 2.5 \text { a } 3.5 \\
\text { cm de largo }\end{array}$ & $\begin{array}{l}\text { morados, } \\
4 \mathrm{~cm} \text { de largo }\end{array}$ & $\begin{array}{l}\text { blancos hacia } \\
\text { la base, lilas } \\
\text { hacia el ápice, } \\
5.1 \text { a } 6 \mathrm{~cm} \\
\text { de largo }\end{array}$ & $\begin{array}{l}\text { morados, } \\
2 \mathrm{~cm} \text { de largo }\end{array}$ \\
\hline Anteras & $\begin{array}{l}\text { conectivo } \\
\text { amarillo }\end{array}$ & $\begin{array}{l}\text { conectivo } \\
\text { desconocido }\end{array}$ & $\begin{array}{l}\text { conectivo } \\
\text { amarillo }\end{array}$ & $\begin{array}{l}\text { conectivo } \\
\text { pardusco }\end{array}$ & $\begin{array}{l}\text { conectivo } \\
\text { desconocido }\end{array}$ & $\begin{array}{l}\text { conectivo } \\
\text { negro }\end{array}$ & $\begin{array}{l}\text { conectivo } \\
\text { desconocido }\end{array}$ & $\begin{array}{l}\text { conectivo } \\
\text { amarillo }\end{array}$ & $\begin{array}{l}\text { conectivo } \\
\text { desconocido }\end{array}$ \\
\hline Estigma & verde & se desconoce & morado & verde & se desconoce & verde & se desconoce & verde & se desconoce \\
\hline Distribución & $\begin{array}{l}\text { México } \\
\text { (Guerrero) }\end{array}$ & \begin{tabular}{|l} 
E.U.A., México \\
a Guatemala
\end{tabular} & $\begin{array}{l}\text { México } \\
\text { (centro y sur) }\end{array}$ & $\begin{array}{l}\text { México } \\
\text { (Colima y } \\
\text { Jalisco) }\end{array}$ & $\begin{array}{l}\text { México (estados } \\
\text { del Pacífico y } \\
\text { del Golfo) Anti- } \\
\text { Ilas y Centro- } \\
\text { américa }\end{array}$ & $\begin{array}{l}\text { México, } \\
\text { Antillas, } \\
\text { Centro } \\
\text { y Sudamérica }\end{array}$ & $\begin{array}{l}\text { México } \\
\text { (Guerrero y } \\
\text { Oaxaca) }\end{array}$ & $\begin{array}{l}\text { México } \\
\text { (Guerrero) }\end{array}$ & $\begin{array}{l}\text { E.U.A., México } \\
\text { (estados del } \\
\text { Pacífico) } \\
\text { Centroamérica } \\
\text { y Brasil }\end{array}$ \\
\hline $\begin{array}{l}\text { Tipos de } \\
\text { vegetación }\end{array}$ & $\begin{array}{l}\text { BQ, BMM y } \\
\text { BP-Q }\end{array}$ & $\begin{array}{l}\text { BQ, BQ-Py } \\
\text { BTC }\end{array}$ & $\begin{array}{l}\text { BQ, BQ-Py } \\
\text { BTC }\end{array}$ & MX & $\begin{array}{l}\text { BP, BTS, BTSP } \\
\text { y BTP }\end{array}$ & $\begin{array}{l}\text { BP-Q, BTS, } \\
\text { BTC, BQ, } \\
\text { BMM y MX }\end{array}$ & BTC & $\begin{array}{l}\text { BQ, BMM } \\
\text { y } M X\end{array}$ & BTS y BTC \\
\hline $\begin{array}{l}\text { Altitud } \\
\text { (metros) }\end{array}$ & $2,200-2,440$ & $50-2,100$ & $1,700-2,600$ & 0 & $0-1,050$ & $250-2,200$ & 150 & $1,890-2,700$ & $40-50$ \\
\hline
\end{tabular}




\section{María Flores-Cruz y María Valentina Diego-Escobar}

ilustración y a Martha Martínez Gordillo, la elaboración de la diagnosis en latín. El trabajo de campo fue apoyado por el Laboratorio de Plantas Vasculares, Facultad de Ciencias, Universidad Nacional Autónoma de México, Programa de Apoyo a Proyectos de Investigación e Innovación Tecnológica (IN223705) y el Colegio de Postgraduados. Estos resultados son parte de la investigación de la tesis de maestría de la segunda autora. Se agradece también el apoyo del Consejo Nacional de Ciencia y Tecnología por la beca otorgada (17185) a la segunda autora.

\section{Literatura citada}

Brown G.K. y Gilmartin A.J. 1984. Stigma structure and variation in Bromeliaceae-Neglected taxonomic characters. Brittonia 36:364-374.

Brown G.K. y Gilmartin A.J. 1989. Stigma types in BromeliaceaeA systematic survey. Systematic Botany 14:110-132.

Diego-Escobar M.V. 2005. El género Tillandsia (Bromeliaceae) en el estado de Guerrero, México. Tesis de maestría, Colegio de Postgraduados, Montecillo, Estado de México, 215 pp.

Eguiarte L.E. 1983. Biología floral de Manfreda brachystachya (Cav.) Rose en el Pedregal de San Angel, México, D.F. Tesis profesional, Facultad de Ciencias, Universidad Nacional Autónoma de México, México, D.F., 72 pp.

Espejo A. y López-Ferrari A.R. 1998. Current floristic and phytogeographic knowledge of Mexican Bromeliaceae. Revista de Biología Tropical 46:493-513.

Espejo-Serna A., López-Ferrari A.R., Ramírez-Morillo I., Holst
B.K., Luther H.E. y Till W. 2004. Checklist of Mexican Bromeliaceae, with notes on species distribution and levels of endemism. Selbyana 25:33-86.

Faegri K. y van der Pijl L. 1979. The Principles of Pollination Ecology. 3a ed., Pergamon Press, Nueva York, N.Y.

Flores-Cruz M. 1998. Flora genérica de la familia Bromeliaceae en el Estado de México. Manual para la identificación de las especies de la familia Bromeliaceae presentes en el Estado de México. Tesis de maestría, Facultad de Ciencias, Universidad Nacional Autónoma de México, México, D.F., 186 pp.

García-Franco J. 1987. Las bromelias de México. Instituto Nacional de Investigaciones sobre Recursos Bióticos. Xalapa, Veracruz.

Gardner C.S. 1982. A systematic study of Tillandsia subgenus Tillandsia. Tesis doctoral. Texas. A \& M University, College Station, Texas, 305 pp.

Gardner C.S. 1986. Preliminary classification of Tillandsia based on floral characters. Selbyana 9:130-146.

Luther H.E. (Comp.) 2000. An Alphabetical List of Bromeliad Binomials. 7a. ed. Bromeliad Society International, Sarasota, Florida.

Sandoval-Bucio E.N., Flores-Cruz M. y Martínez-Bernal A. 2004. Bromelias útiles de México. Cactáceas y Suculentas Mexicanas 49:100-115.

Smith, L.B. y Downs R.J. 1977. Tillandsioideae (Bromeliaceae). Flora Neotropica Monograph 14, part 2:663-1492.

Utley J.F. 1994. Bromeliaceae. En: Davidse, G., Sousa S. M. y Charter A.O. Eds. Flora Mesoamericana Vol. 6., pp. 89-156. Universidad Nacional Autónoma de México, Missouri Botanical Garden, y The Natural History Museum (London), México, D.F.

Recibido: 29 de octubre de 2007

Aceptado: 12 de abril de 2008 